Article

\title{
MicroRNA Expression Profile Analysis of Chlamydomonas reinhardtii during Lipid Accumulation Process under Nitrogen Deprivation Stresses
}

\author{
Jingxian Zhang ${ }^{1,2}$, Jiping Shi ${ }^{1,2,3}$, Chenyang Yuan ${ }^{1,2,3}$, Xiangcen Liu ${ }^{1,2}$, Guilin Du $1,2,3$, Ruimei Fan ${ }^{4, *}$ \\ and Baoguo Zhang $1,2, *$ (D)
}

check for

updates

Citation: Zhang, J.; Shi, J.; Yuan, C.; Liu, X.; Du, G.; Fan, R.; Zhang, B. MicroRNA Expression Profile Analysis of Chlamydomonas reinhardtii during Lipid Accumulation Process under Nitrogen Deprivation Stresses. Bioengineering 2022, 9, 6 .

https://doi.org/10.3390/

bioengineering 9010006

Academic Editors: Giorgos Markou and Zhi-Yong Li

Received: 18 November 2021

Accepted: 21 December 2021

Published: 27 December 2021

Publisher's Note: MDPI stays neutral with regard to jurisdictional claims in published maps and institutional affiliations.

Copyright: (c) 2021 by the authors Licensee MDPI, Basel, Switzerland. This article is an open access article distributed under the terms and conditions of the Creative Commons Attribution (CC BY) license (https:// creativecommons.org/licenses/by/ $4.0 /)$.
1 Lab of Biorefinery, Shanghai Advanced Research Institute, Chinese Academy of Sciences, No. 99 Haike Road, Pudong, Shanghai 201210, China; zhangjingxian@sari.ac.cn (J.Z.); shijp@sari.ac.cn (J.S.); yuanchy@shanghaitech.edu.cn (C.Y.); jpk9999@aliyun.com (X.L.); dug11@shanghaitech.edu.cn (G.D.)

2 University of Chinese Academy of Sciences, Beijing 100049, China

3 School of Life Science and Technology, ShanghaiTech University, Shanghai 201210, China

4 Sino-UK Joint Laboratory for Brain Function and Injury and Department of Physiology and Neurobiology, Xinxiang Medical University, Xinxiang 453003, China

* Correspondence: ruimaifan@gmail.com (R.F.); zhangbg@sari.ac.cn (B.Z.)

\begin{abstract}
Lipid accumulation in various microalgae has been found induced by nitrogen deprivation, and it controls many different genes expression. Yet, the underlying molecular mechanisms still remain largely unknown. MicroRNA (miRNAs) play a critical role in post-transcriptional gene regulation. In this study, miRNAs were hypothesized involved in lipid accumulation by nitrogen deprivation. A deep-sequencing platform was used to explore miRNAs-mediated responses induced by nitrogen deprivation in Chlamydomonas reinhardtii. The eukaryotic orthologous groups of proteins (KOG) function in the predicted target genes of miRNA with response to nitrogen deprivation were mainly involved in signal transduction mechanisms, including transcription, lipid transport, and metabolism. A total of 109 miRNA were predicted, including 79 known miRNA and 30 novel miRNA. A total of 29 miRNAs showed significantly differential expressions after nitrogen deprivation, and most of them were upregulated. A total of 10 miRNAs and their targeting genes might involve in lipid transport and metabolism biological process. This study first investigates nitrogen deprivationregulated miRNAs in microalgae and broadens perspectives on miRNAs importance in microalgae lipid accumulation via nitrogen deprivation. This study provides theoretical guidance for the application of microalgae in bio-oil engineering production.
\end{abstract}

Keywords: microRNA; Chlamydomonas reinhardtii; lipid; nitrogen deprivation

\section{Introduction}

The development toward clean and sustainable biofuels has gained significant support due to petroleum supply, global climate change, and energy shortage [1,2]. Compared with terrestrial biomass, microalgae have excellent photosynthetic efficiency, lipid content, and shorter cultivation time. Therefore, the search for a sustainable source of biofuel has renewed interest in microalgae as a potential feedstock [3]. Production of lipids by microalgae is usually because of environmental stresses, and many microalgae have the ability to accumulate large quantities of lipids when nutrient-deprived [4], particularly nitrogen deprived. For example, cyanobacteria showed an average increase of $9.8 \%$ in lipid content under nitrogen-depletion conditions [4]. The green microalga S. dimorphus (UTEX 1237 ) increased body lipids in N-limited cultures [5]. On average, an increase of 63\%, 40\%, and $23 \%$ in total lipids was obtained from Chlorella emersonii, Chlorella vulgaris, and Chlorella pyrenoidosa grown under nitrogen-depletion conditions, respectively [6]. In Chlorella vulgaris, the highest lipid content (ca. $36 \mathrm{wt}$ \% on dry biomass) was obtained 
without nitrogen cultivation [7]. It has been reported that adding nitrogen and iron extracts to the nitrogen-deficient medium can promote the biomass accumulation of Chlorella and increase the lipid content [8]. Several recent studies have explored the mechanisms of lipids accumulation under nutrient deprivation. Chlamydomonas reinhardtii, as one of the most thoroughly characterized unicellular alga, has been mostly studied due to its rapid growth under nutritionally limited conditions and its low culture cost. The completion state of the Chlamydomonas genome, including sequence, assembly, and annotation, currently stands for a standard to determine if other algae should aspire [9]. Therefore, Chlamydomonas reinhardtii is undoubtedly the most suitable choice in solving the problems that this research focuses on. Many genes related to nitrogen import and assimilation have been found induced with nitrogen deprivation [10-13]. For example, in Chlamydomonas reinhardtii, the CrABCA2 protein level also increased through CrABCA2 expression upregulated under nitrogen deprivation conditions [14]. DGTT4 transcript was also upregulated notoriously under nitrogen depletion [12]. Nitrogen deprivation could activate a subset of control genes involved in gametogenesis, down-regulate protein biosynthesis, and lead to a marked redirection on its metabolism [15]. Recent studies have shown that down-regulating of the expression of flagella-associated WDR-containing protein CrFAP89 in C. reinhardtii, resulting in a decrease in fatty acid synthesis, but the transcription levels of CrFAP89 were significantly enhanced upon nitrogen deprivation [16]. Nitrogen deprivation also results in photosynthetic hydrogen production in C. reinhardtii [17]. However, its underlying molecular mechanisms about lipids accumulation under nitrogen deprivation are far from being completely understood, and the subcellular localization of the mechanism of TAG synthesis in microalgae is even unclear $[18,19]$. This work revealed changes in the expression of target genes by analyzing the major expression of microRNAs under nitrogen stress, and provided suggestions for the gene regulation of lipid accumulation in Chlamydomonas reinhardtii under nitrogen stress. This work fills in the knowledge gap of microRNAs regulation for gene expression under nitrogen stress.

MicroRNAs (miRNAs) are endogenous non-protein-coding RNAs with a length of approximately 22 nucleotides (nt), which is widely found in animals and plants, including unicellular green algae $[20,21]$. miRNAs could regulate the post-transcriptional gene expression by guiding both mRNA degradation and translational repression. Numerous studies have demonstrated that miRNAs play an important role in many biological and metabolic processes [22]. Identification of miRNAs expression profiles in organisms is a critical step to understanding the role of miRNAs executed in a specific biological process. Recently, more and more miRNAs profiles have been analyzed and detected out $[23,24]$. In addition, this discovery on large numbers of miRNAs has made some miRNAs find more important functions in the adaptive responses toward diverse abiotic stresses, including nutrient deficiency, cold, drought, high salinity, and UV-B radiation [20,25,26]. More interestingly, some miRNAs also have been found to play an important role in lipid metabolisms. For example, deletion of miR14 was found to be able to increase lipids accumulation in Drosophila [27]; miR-148a can regulate lipid metabolism by hepatic lipid content by inhibiting LDLR expression activity [28]. Compared with those in wild-type mice, ABCA1, ABCG1, and SREBP-1 on miR-33 related sterol metabolism were reduced in miR-33b knock-in (KI) mice, [29]; miR-122, triggered on key enzymes on the fatty acid synthesis and oxidation, also showed a relevant function for fatty acid metabolism. However, little information in microalgae under nitrogen deficiency stress is available at miRNA in the regulation of lipids accumulation.

Recently, high-throughput sequencing technology has been used as a powerful strategy to analyze miRNA expression patterns, detect novel miRNAs, and identify other functional small RNAs from an unprecedented perspective [30]. In this study, Chlamydomonas reinhardtii, which is usually the primary molecular model of microalgae, was subjected to deep sequencing and bioinformatics analysis. This work was performed to identify unknown and novel miRNAs and to determine major changes in miRNAs expression during nitrogen deprivation. These findings in this study would provide a novel insight into the molecular 
mechanisms that mediated nitrogen deprivation stress and a broader understanding of the induction of lipid accumulation in microalgae.

\section{Materials and Methods}

\subsection{Strains and Culture Conditions}

The C. reinhardtii CC-503 (cw92 $\mathrm{mt}+$ ) used in this study were obtained from the Chlamydomonas Center, Duke University, Durham, NC, USA. The cells were grown in liquid cultures under continuous light (approximately $80 \mu \mathrm{mol}$ photons $\mathrm{m}^{-2} \mathrm{~s}^{-1}$ ). The culture medium used in this study included Tris-acetate phosphate (TAP) liquid culture and nitrogen-depleted TAP (TAP-N) culture medium [15]. TAP medium consisted of $\mathrm{NH}_{4} \mathrm{Cl}(7.48 \mathrm{mM}), \mathrm{MgSO}_{4}(406 \mu \mathrm{M}), \mathrm{CaCl}_{2}(340 \mu \mathrm{M}), \mathrm{K}_{2} \mathrm{HPO}_{4}(540 \mu \mathrm{M}), \mathrm{KH}_{2} \mathrm{PO}_{4}(463 \mu \mathrm{M})$, $20 \mathrm{mM}$ Tris, $17.4 \mathrm{mM}$ acetate, $\mathrm{H}_{3} \mathrm{BO}_{3}(184 \mu \mathrm{M}), \mathrm{ZnSO}_{4}(76.5 \mu \mathrm{M}), \mathrm{MnCl}_{2}(25.5 \mu \mathrm{M}), \mathrm{FeSO}_{4}$ $(17.9 \mu \mathrm{M}), \mathrm{CoCl}_{2}(6.77 \mu \mathrm{M}),\left(\mathrm{NH}_{4}\right)_{6} \mathrm{Mo}_{7} \mathrm{O}_{24}(0.88 \mu \mathrm{M}), \mathrm{CuSO}_{4}(6.29 \mu \mathrm{M})$ and $\mathrm{Na}_{2} \mathrm{EDTA}$ $(148 \mu \mathrm{M})$. TAP-N medium was prepared from TAP by eliminating $\mathrm{NH}_{4} \mathrm{Cl}$. For the nitrogen deprivation experiment, $C$. reinhardtii CC-503 was firstly grown in TAP culture medium to $5 \times 10^{6}$ cells $\mathrm{mL}^{-1}$, followed by transfer to TAP-N culture medium for an additional $72 \mathrm{~h}$. Cells cultures were grown in $500 \mathrm{~mL}$ shaker flasks with a culture volume of $100 \mathrm{~mL}$ with continuous shaking. Each experiment is repeated at least 3 times independently. The reagents used in this study were purchased from Shanghai Macklin Biochemical Co (Shanghai, China).

\subsection{Lipid Analysis}

\subsubsection{Nile Red Fluorescence Determination of Neutral Lipid}

Nile red is a dibenzoxazine dye, easily soluble in organic solvents but extremely insoluble in water [31]. It is an excellent lysochrome dye and is widely used for dyeing lipid-producing microalgae [32]. Compared with the oil red o staining method, the Nile red staining method is easier to operate [31]. During the cultivation of Chlamydomonas reinhardtii, the lipophilic reagent Nile red is used to estimate the lipid content by colorimetry so that lipids can be directly quantified [8].

A stock solution of Nile red was prepared by adding $5 \mathrm{mg}$ of Nile red to $100 \mathrm{~mL}$ of acetone [32]. The solution is stored in an amber bottle at $4{ }^{\circ} \mathrm{C}$ and protected from light. Transfer about $150 \mu \mathrm{L}$ of algae cell suspension (TAP and TAP-N medium) to 96-well plates with a transparent bottom. Add $5 \mu \mathrm{L}$ of Nile red solution to each well, mix well, and incubate for $15 \mathrm{~min}$ at $37^{\circ} \mathrm{C}$ in the dark. Finally, a 96-well microplate reader (Synergy H1, Bio-Tek Instruments, Winooski, VT, USA) was used to quantify the cell neutral lipids with an excitation wavelength of $485 \mathrm{~nm}$ and an emission wavelength of $595 \mathrm{~nm}$ [33].

\subsubsection{Lipid Extraction}

One hundred mg (dry weight) of algal cultures were harvested by centrifugation $(5000 \times g \times 5 \mathrm{~min})$ and subsequently freeze-dried for at least $6 \mathrm{~h}$. The lipids were extracted with $10 \mathrm{~mL}$ of chloroform:methanol (2:1), and the extract was centrifuged at $3000 \times g$ (Eppendorf centrifuge 5804R, Hamburg, Germany) for $10 \mathrm{~min}$ for phase separation [34]. Remove the upper layer (methanol water layer) and collect the lipid-containing chloroform layer. The chloroform was evaporated from the extract to produce the resulting algae oil, which was analyzed by GC-MS [33].

\subsubsection{Fatty Acid Determination}

The fatty acid profile of the lipid sample was determined by converting the fatty acids in the lipid to fatty acid methyl esters (FAMEs). The FAME composition was determined using an Agilent $6890 \mathrm{~N}$ gas chromatography instrument coupled with an Agilent 5975 mass-selective detector and an Agilent autosampler 7683-B injector (Agilent Technologies, Palo Alto, CA, USA). A DB-624 capillary column with a dimension of $30 \mathrm{~m} \times 0.32 \mathrm{~mm}$ ID $\times 1.80 \mu \mathrm{m}$ film thicknesses (Agilent Technologies, Palo Alto, CA, USA) was used for the chromatographic separation. Details of the procedure have been described elsewhere [33]. 
Keep the column at $120^{\circ} \mathrm{C}$ for $1 \mathrm{~min}$, then increase it to $240^{\circ} \mathrm{C}$ at a rate of $20^{\circ} \mathrm{C} / \mathrm{min}$, and then keep it at $240{ }^{\circ} \mathrm{C}$ for $13 \mathrm{~min}$. The transfer line between GC and MS was kept at $240{ }^{\circ} \mathrm{C}$.

\subsection{Small RNA Library Construction and Deep Sequencing}

To generate material for high-throughput sequencing, C. reinhardtii CC-503 was grown

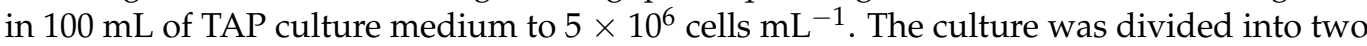
halves, the cells were collected by centrifugation, and one pellet was resuspended in $50 \mathrm{~mL}$ TAP medium and the other pellet in $50 \mathrm{~mL}$ TAP-N medium. After $48 \mathrm{~h}$, the total RNA was isolated from TAP and TAP-N cells as described above by using Trizol reagent (Invitrogen, Life Technologies, Carlsbad, CA, USA) according to the manufacturer's instructions. The RNA quality and quantity were determined using an Agilent 2100 Bioanalyzer (Agilent, Santa Clara, California, USA).

The nitrogen deficiency small RNA library: equal quantities $(20 \mu \mathrm{g})$ of total RNA isolated from TAP-N culture medium with three parallel experiments were mixed to construct.The control small RNA library: equal quantities $(20 \mu \mathrm{g})$ of total RNA isolated from the TAP culture medium with three parallel experiments were mixed to construct. Then, the two different samples were subjected to $15 \%$ denaturing polyacrylamide gel electrophoresis, after which the small RNA fragments of 18-30 nt were isolated from the gel and purified. Next, the small RNA molecules have ligated a pair of Solexa adaptors to their $5^{\prime}$ and $3^{\prime}$ ends and then converted to DNA by RT-PCR. Finally, according to the manufacturer's protocols (Beijing Genomics Institute, Beijing, China), approximately $20 \mathrm{mg}$ of RT-PCR products were directly sequenced using So-lexa 1G Genome Analyzer.

\subsection{Sequence Analysis}

After Solexa sequencing, the adaptor/acceptor sequences were removed, the lowquality tags were filtered out, and the contamination of adaptor sequences was cleaned up. The resulting set of each unique sequence with associated read counts was referred to as clean sequence tags. For noncoding RNAs identification, the clean sequences were compared with rRNA, tRNA, snRNA, and snoRNA deposited in Rfam (http://www. sanger.ac.uk/Software/Rfam, accessed on 29 May 2021) and the GenBank noncoding RNA database (http:/ / www.ncbi.nlm.nih.gov/, accessed on 29 May 2021). In addition, all sequences, discarding redundancy, were searched against miRBase (Release 14.0; http: / / microrna.sanger.ac.uk/, accessed on 29 May 2021) to identify known miRNAs in C. reinhardtii. Only the perfectly matched sequences were considered to be known miRNAs.

The prediction of the novel miRNA of Chlamydomonas reinhardtii is based on the previously established standards for plant miRNA prediction [35]. Sequences with a perfect match or with one mismatch were retained for further analysis. The secondary structures of the small RNA precursor were obtained using the RNAfold program (http: / / rna.tbi.univie.ac.at/cgi-bin/RNAWebSuite/RNAfold.cgi, accessed on 3 June 2021). Then, the novel miRNAs were identified using the MIREAP program developed by the BGI (Beijing Genome Institute, https:/ / sourceforge.net/projects/mireap/, accessed on 5 June 2021). Finally, the RNA secondary structure was checked using Mfold.

\subsection{The Nitrogen Deprivation-Responsive miRNAs in C. reinhardtii}

To compare the miRNAs expression between $C$. reinhardtii cultured in TAP and TAP-N medium and to determine the responsive miRNAs in C. reinhardtii at nitrogen deprivation, the expression of miRNAs in two samples (culture with TAP and TAP-N medium, respectively) were normalized to obtain the expression of transcripts per million (TPM). If the normalized expression of a given miRNA is zero, its expression value will be modified to 0.01. If the normalized expression of a given miRNA is less than 1 in both samples, this miRNA is removed in future differential expression analysis [36].

The fold change between treatment and control was calculated as:

Normalized expression $(\mathrm{NE})=$ Actual miRNAs sequencing count/

Total count of clean reads $\times 1,000,000$ 
Fold change $=\log _{2}(\mathrm{TAP}-\mathrm{N} / \mathrm{TAP})$

Then, perform statistical analysis based on Poisson distribution. Calculate the $p$-value according to the formula [37].

$$
\begin{gathered}
P(x \mid y)=\left(\frac{N_{2}}{N_{1}}\right) \frac{(x+y) !}{x ! y !\left(1+\frac{N_{2}}{N_{1}}\right)^{(x+y+1)}} \\
C=\left(\gamma \leq \gamma_{\min } \mid x\right)=\sum_{\gamma=0}^{\gamma \leq \gamma_{\min }} p(\gamma \mid x) \\
D=\left(\gamma \geq \gamma_{\max } \mid x\right)=\sum_{\gamma \geq \gamma_{\max }}^{\infty} p(\gamma \mid x)
\end{gathered}
$$

The $N_{1}$ and $x$ represent the total count of clean reads and normalized expression level of a given miRNA in the small RNA library of the TAP library sample, respectively. The $\mathrm{N}_{2}$ and $y$ represent the total count of clean reads and normalized expression level of a given miRNA in the small RNA library of the TAP-N library sample, respectively.

\subsection{The Target Nitrogen Deprivation-Responsive miRNAs and KOGs Analysis}

To understand the molecular function of the nitrogen deprivation-responsive miRNAs in C. reinhardtii, the target gene prediction was carried out as described by Allen et al. [35] and Schwab et al. [38]. The prediction was subject to the following rules: (1) between the small RNA and the target no more than four mismatches (G-U bases count as 0.5 mismatches); (2) no more than two adjacent mismatches in the miRNA: target duplex; (3) no adjacent mismatches in positions 2-12 of the miRNA: target duplex (5' of miRNA); (4) no mismatches in positions 10-11 of the miRNA: target duplex; (5) No more than 2.5 mismatches in positions 1-12 of the miRNA: target duplex ( $5^{\prime}$ of miRNA); (6) The minimum free energy (MFE) of the miRNA/target duplex should be greater than $75 \%$ of the MFE of the miRNA bound to its perfect complement. The functional category of obtained target genes was annotated against the KOG database (http:/ / genome.jgi-psf.org/cgi-bin/ kogBrowser? $\mathrm{db}=$ Chlre 4 , accessed on 10 June 2021) using BLAST program with a cutoff of $\mathrm{E}$ value $<1 \times 10^{-5}$.

\section{Results}

3.1. Analysis on Lipid and Fatty Acid Composition of C. reinhardtii under Nitrogen-Replete and Nitrogen-Deprived Conditions

The Nile red fluorescence method, excellently applied to many microalgae, was used to determine the relative lipid content of C. reinhardtii under nitrogen-deprived conditions [32]. Cell density was determined by measuring the optical densities of the cultures. Figure 1 shows the relative neutral lipid content per OD unit under these culture conditions, as measured by Nile red fluorescence. After the two days of nitrogen deprivation, C. reinhardtii accumulated substantial amounts of lipid and but declined after day 3 . However, cells in a nitrogen-replete medium accumulated relatively little lipid until day 3 . This result showed that the lipid content of $C$. reinhardtii could be increased under nitrogen deprivation stress. 


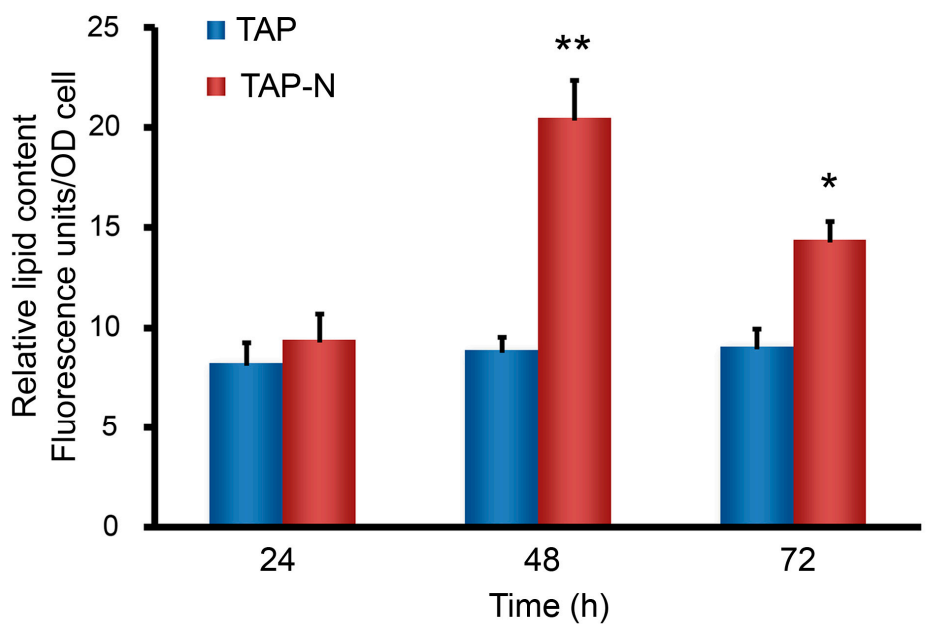

Figure 1. Lipid accumulation in nitrogen-deprived cells. C. reinhardtii cultures cultivated in nitrogenreplete medium (TAP) and nitrogen deficiency medium (TAP-N) were stained with Nile red on days 1,2 , and 3. Neutral lipid content was measured by determining Nile red fluorescence. ${ }^{*} p<0.05$, ** $p<0.01$ versus littermate controls by two-way ANOVA.

The chemical property of fatty acid esters, such as the unsaturation degree and carbon chain length, determine cetane number, viscosity, cold flow, oxidative stability, and iodine value related to biodiesel [39]. Therefore, the fatty acid profiles of lipid present in $C$. reinhardtii were analyzed by lipid extraction, transesterification, and fatty acid methyl esters (FAME) obtained by GC-MS analysis. The fatty acid profiles of the $C$. reinhardtii are presented in Table 1. Overall, C16:0, C18:0, C16:1 $\omega, \mathrm{C} 18: 2 \omega, \mathrm{C} 18: 3 \omega$, and C20:2 $\omega$ were the major fatty acid under these two culture conditions. The most abundant saturated and unsaturated fatty acid was C16:0 (about $17-18 \%$ ) and C18:3 $\omega$ (about 24-32\%), respectively. However, the total saturated fatty acids and the total unsaturated fatty acid displayed a significant interaction under nitrogen deficiency conditions. Under nitrogen deficiency conditions, $C$. reinhardtii contained a more saturated fatty acid (about $41.96 \%$ ) but a lower unsaturated fatty acid (about $58.04 \%$ ) as compared with that from normal conditions (about $34.26 \%$ and $65.74 \%$, respectively).

Table 1. Fatty acid profile (percentage of total fatty acids) of extracted lipids from C. reinhardtii, which were cultivated in nitrogen-replete medium (TAP) and in nitrogen deficiency medium (TAP-N). Values are means of three replicates. Cells harvested after $48 \mathrm{~h}$ of cultivation.

\begin{tabular}{|c|c|c|}
\hline \multirow{2}{*}{ Fatty Acid (\%) } & \multicolumn{2}{|c|}{ C. reinhardtii Based Biodiesel } \\
\hline & TAP & TAP-N \\
\hline C14:0 & $1.40 \pm 0.43$ & $3.95 \pm 0.13$ \\
\hline C16:0 & $17.05 \pm 0.28$ & $18.07 \pm 0.70$ \\
\hline $\mathrm{C} 16: 1 \omega 7$ & $1.47 \pm 0.39$ & $3.00 \pm 0.24$ \\
\hline C18:0 & $12.17 \pm 0.46$ & $11.75 \pm 0.69$ \\
\hline C16:1w9 & $8.27 \pm 0.91$ & $10.59 \pm 0.14$ \\
\hline $\mathrm{C} 18: 2 \omega 6$ & $4.49 \pm 0.94$ & $7.87 \pm 1.35$ \\
\hline C20:0 & $1.56 \pm 0.48$ & $3.52 \pm 0.59$ \\
\hline $\mathrm{C} 18: 3 \omega 3$ & $32.63 \pm 1.79$ & $24.40 \pm 0.63$ \\
\hline C21:0 & $1.25 \pm 0.34$ & $2.19 \pm 0.38$ \\
\hline $\mathrm{C} 20: 2 \omega 6$ & $13.45 \pm 0.72$ & $9.22 \pm 0.87$ \\
\hline C20:3w6 & $2.19 \pm 0.11$ & $2.24 \pm 0.11$ \\
\hline $\mathrm{C} 22: 4 \omega 6$ & $0.94 \pm 0.43$ & $0.33 \pm 0.43$ \\
\hline Other & $3.13 \pm 1.14$ & $2.88 \pm 0.25$ \\
\hline$\sum$ Unsaturat & $65.74 \pm 2.58$ & $58.04 \pm 1.88$ \\
\hline$\sum$ Saturat & $34.26 \pm 1.23$ & $41.96 \pm 1.52$ \\
\hline
\end{tabular}




\subsection{Deep Sequencing of C. reinhardtii Small RNAs}

To investigate $C$. reinhardtii small RNA under nitrogen deprivation stress, two small RNA libraries, TAP and TAP-N culture medium, were generated using the pooled RNA isolated from C. reinhardtii. These two C. reinhardtii small RNA libraries were sequenced by a deep-sequencing technology Solexa to produce highly accurate, reproducible, and quantitative readouts of small RNAs. Solexa sequencing of TAP and TAP-N libraries generated a total number of 15,360,483 and 16,105,446 raw reads, respectively. After removing adaptor/acceptor sequences, filtering out low-quality tags, and cleaning up the contamination from the adaptor-adaptor ligation, a total number of 28,362,008 clean reads from the two libraries $(13,790,887$ and $14,571,121$, read from TAP and TAP-N libraries, respectively) were obtained with 891,186 , and 1,403,685 unique reads, respectively. These unique sequences contained 220,552 common sequences between TAP and TAP-N libraries, 670,634 TAP-specific sequences, and 1,183,133 TAP-N-specific sequences (Table S1 and Figures S1 and S2), showing that TAP-N small RNA libraries had a higher unique sequences tag. The results also indicated that nitrogen deprivation affected the small RNA expression patterns in C. reinhardtii. Because small RNAs with known functions are commonly 20-24 nt long [40], the unique size distribution patterns of the small RNA sequence in the two libraries were also analyzed and showed that the majority of small RNA was $21 \mathrm{nt}$ in size, with $20 \mathrm{nt}, 22 \mathrm{nt}$, and $23 \mathrm{nt}$, which is consistent with the typical size of miRNAs from Dicer digestion products (Figure 2).

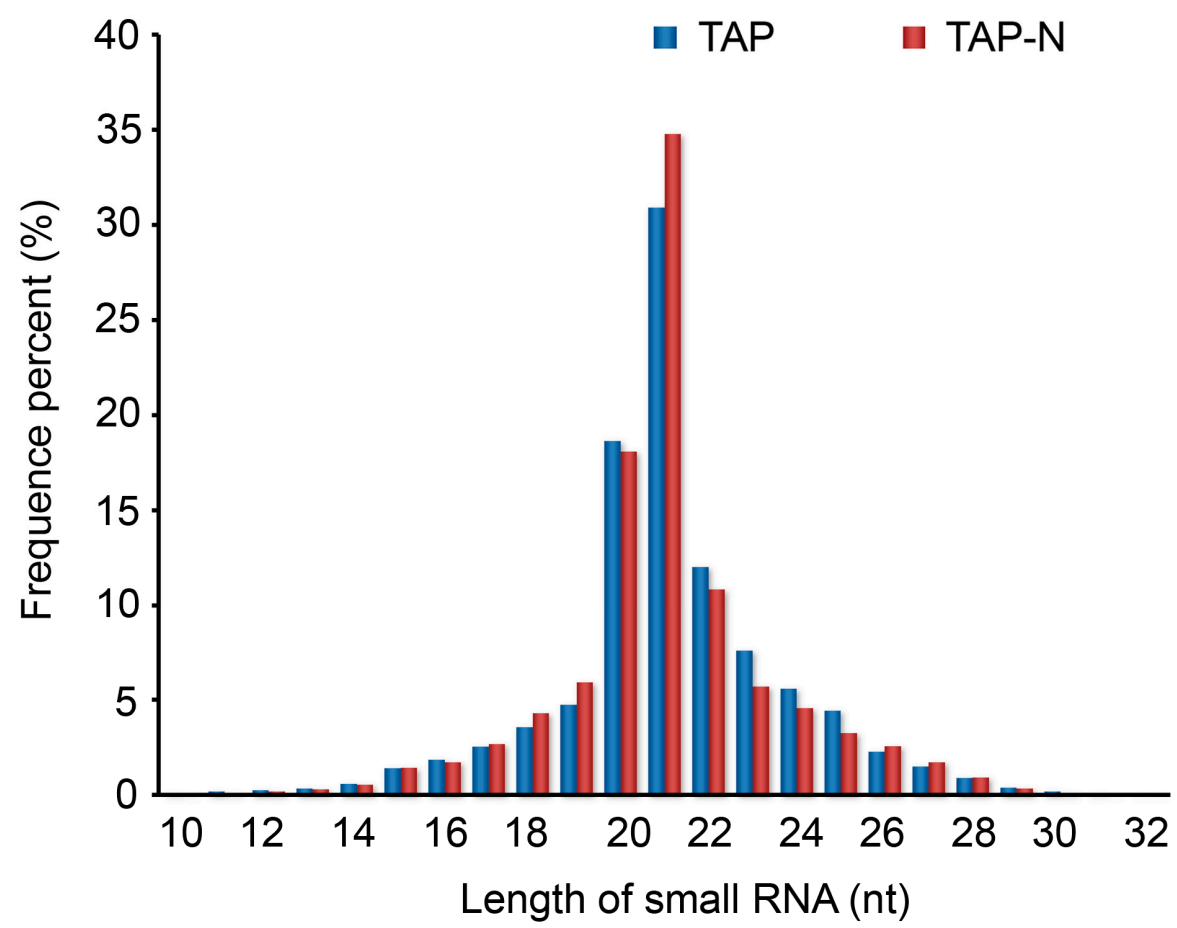

Figure 2. The length size distributions of small RNAs from the libraries of both TAP and TAP-N. The occurrences of each unique sequence read were counted to reflect relative expression level, and only small RNA sequences in the range of 10 to $32 \mathrm{nt}$ were considered. TAP represents unique sequence reads of small RNAs of $C$. reinhardtii cultivated in nitrogen-replete medium; TAP-N represents unique sequence reads of small RNAs of $C$. reinhardtii cultivated in nitrogen deficiency medium.

\subsection{Identification and Profiling of Known miRNAs}

To identify known miRNA homologs in Chlamydomonas reinhardtii, annotate clean sequences based on their similarity with the mature miRNA sequences in miRBase (release 14.0). With this annotation, a total of 79 unique known miRNAs were identified, including 72 C. reinhardtii miRNAs overlapped between the two libraries of one miRNA detected only in the TAP library and 6 miRNAs detected only in the TAP-N library (Table S2). In 
a high-throughput sequencing, the relative expression level of a specific miRNA can be measured by the frequency of its transcript abundance, which could be counted by first normalizing the absolute sequence reads with transcripts per million (TPM) in the two libraries. Based on this measurement, the expression range of specific miRNAs was from less than 10 to more than 10,000 counts (Figure 3). Thus, the sequencing data revealed a wide range of expression levels spanning five times magnitude. For both libraries, the majority of miRNAs $(>70 \%)$ were sequenced with a less than $10 \mathrm{TPM}$. cre-miR1157 was the most highly expressed miRNA in both libraries with $8632 \mathrm{TPM}(\sim 34 \%$ of all miRNAs reads) in the TAP library and 10,783 TPM ( 33\% of all miRNAs reads) in the TAP-N library (Figure 4, Table S2). Moreover, these two libraries shared eight out of the top 10 most frequently expression level miRNAs: cre-miR912, cre-miR919.2, cre-miR1152, cremiR1153.1, cre-miR1153.2, cre-miR1154, cre-miR1157, and cre-miR1162 (Figure 4, Table S2). The sequencing frequency of some other miRNAs, including cre-miR1142, cre-miR1148.1, cre-miR1162*, and cre-miR1163.1, was low in both the libraries. These miRNAs may be expressed at a low level in certain cell types under a certain condition. To investigate the evolutionary roles of these known miRNAs, extensive comparisons have been made against known miRNAs in some other plant species and animals. The results showed no miRNAs with a direct sequence similarity between C. reinhardtii and higher plants/animals.

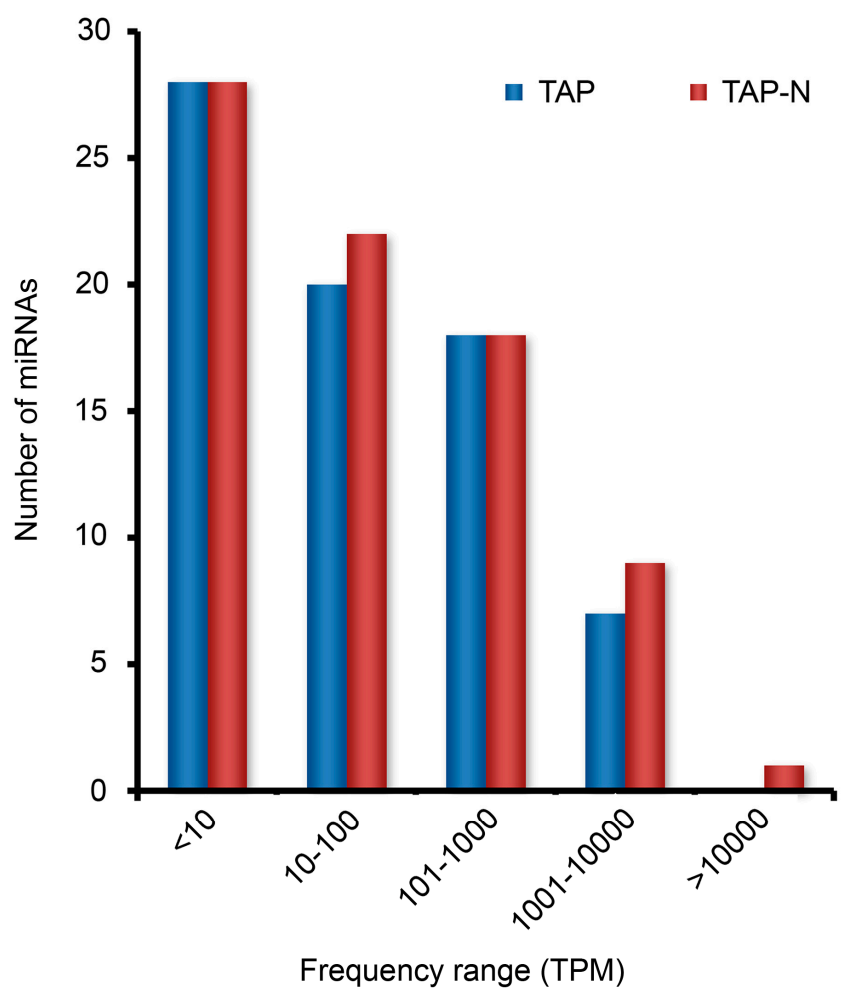

Figure 3. Frequency of read counts (TPM) for individual, known miRNAs presented in TAP and TAP-N libraries. The read count is based on the quantity of reads detected during the deep sequencing of the small RNA library for miRNAs detection was used the miRBase release 14.0. TAP represents read counts of individual, known miRNAs of $C$. reinhardtii cultivated in nitrogen-replete medium; TAP-N represents read counts of individual, known miRNAs of $C$. reinhardtii cultivated in nitrogen deficiency medium. 
(a)

눌

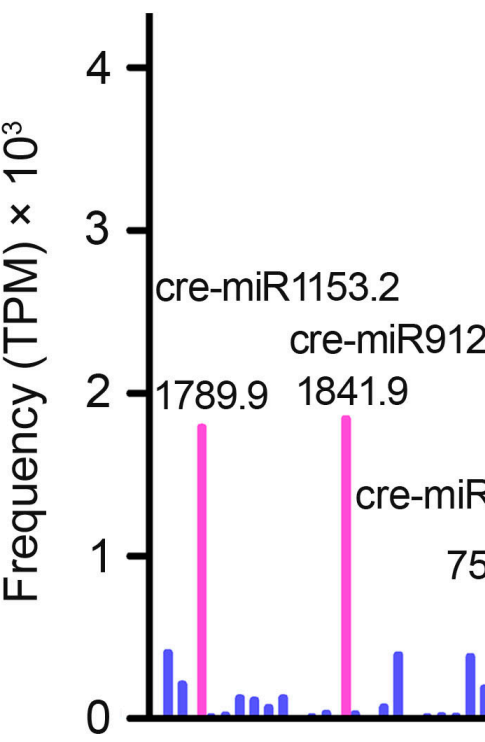

cre-miR1153.1

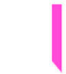

(b)

cre-miR1157

10783.1

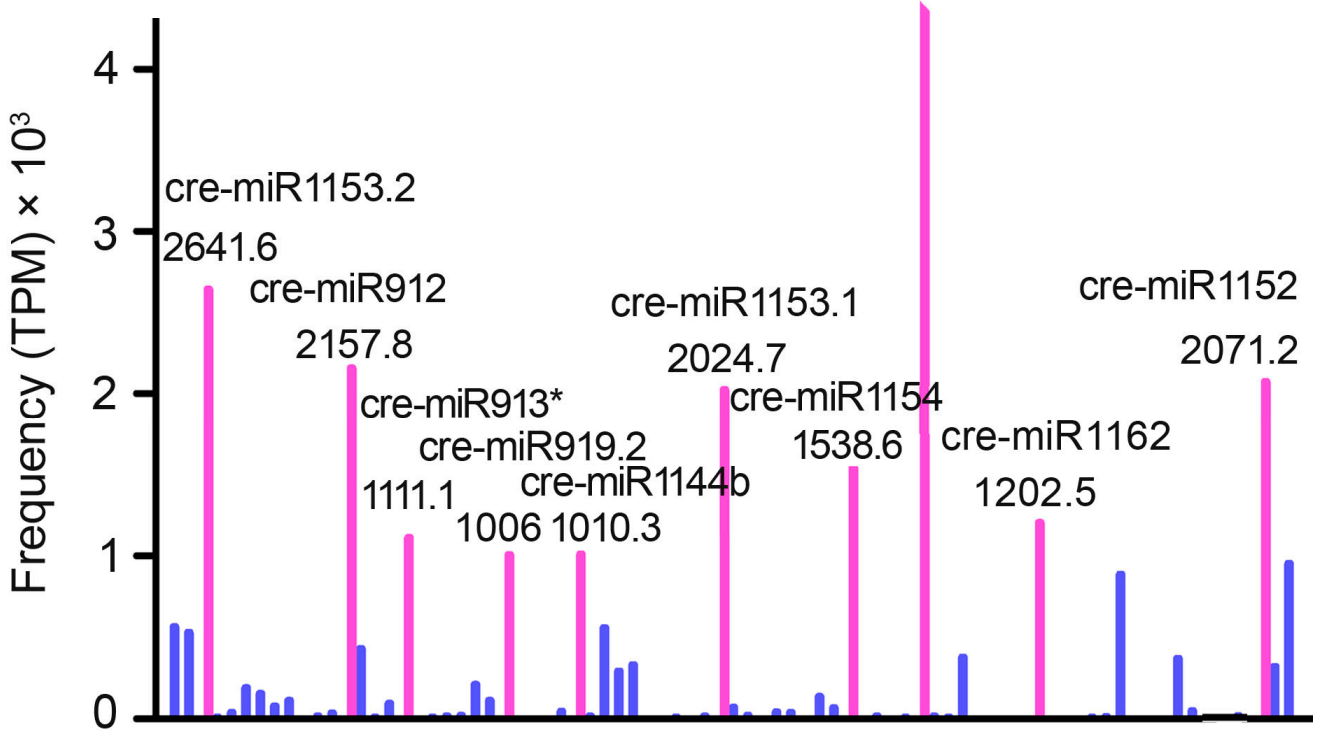

Figure 4. Abundance and differential expression of known miRNAs expressed (TPM) in C. reinhardtii. (a) represents the known miRNAs of $C$. reinhardtii cultivated in nitrogen-replete medium; (b) represents the known miRNAs of $C$. reinhardtii cultivated in nitrogen deficiency medium. Red lines indicated the TOP ten miRNAs; blue lines indicated the relatively less abundant miRNAs.

\subsection{Potential Novel miRNAs}

One most important features of deep sequencing are to be employed in the discovery of novel miRNAs. In this study, a high percentage of small RNAs, $66.61 \%$ in the TAP library and $58.75 \%$ in the TAP-N library were sorted as unannotated RNAs. To check whether novel 
miRNAs were present among unannotated RNAs. In this study, the miReap algorithm (http:/ / sourceforge.net/projects / mireap, accessed on 5 June 2021) was employed to call all the candidate miRNAs precursors with hairpin-like structures perfectly mapped by sequencing reads (seen in material and methods). Subsequently, 30 putative novel miRNAs were identified from the two libraries (Table S3). Of these novel miRNAs, 23 miRNAs were detected in both TAP and TAP-N samples, 5 miRNAs were identified only in the TAP sample, and 2 miRNAs were identified only in the TAP-N sample (Table S3).

The size range of these newly identified miRNAs sequences was from 20 to $23 \mathrm{nt}$, and the length of their predicted hairpin structures was from 62 to $96 \mathrm{nt}$, similar to known $C$. reinhardtii miRNAs. A total of 30 putative novel miRNAs had a negative folding free energy ranging from -54.3 to $-22.3 \mathrm{kcal} \mathrm{mol}^{-1}$ (average value $=-32.4 \mathrm{kcal} \mathrm{mol}^{-1}$ ) according to Mfold. Among these 30 novel miRNAs, 21 miRNAs were encoded by a single copy in the C. reinhardtii genome, whereas the other 9 miRNAs had multiple loci (Table S3), probably leading to duplication events that were still active in the $C$. reinhardtii genome. For these 9 miRNAs, most of them only had 2-5 loci, and 1 miRNA had 9 loci in the genome.

To understand the conservation of the new identified $C$. reinhardtii miRNAs, the novel miRNAs were compared to genomes of species by representing important lineages. The results show that all the novel miRNAs do not have a sequence homologous with the miRNAs gene of other species, which indicated species-specific miRNAs identified in $C$. reinhardtii consistent with the evolutionary character of the known miRNAs in C. reinhardtii.

\subsection{Response of C. reinhardtii miRNAs to Nitrogen Deprivation Stress}

The deep-sequencing approach can be used as a powerful tool for profiling miRNAs expression. The change in miRNAs frequency between the nitrogen deprivation (TAP-N) and control (TAP) libraries might indicate that nitrogen deficiency stress regulates their expression. To determine the response of $C$. reinhardtii miRNAs for nitrogen deprivation, the TPM value changes were compared between TAP-N and TAP libraries to find the miRNAs that were up-or down-regulated under nitrogen deficiency stress in C. reinhardtii. Meantime, to minimize noise and improve accuracy, miRNAs with a frequency no less than 1 TPM value in at least one library were selected for comparison.

Overall, approximately half of known miRNAs with greater than 1.5 fold relative change in TPM value were identified between the two libraries (Table S2). After the nitrogen deprivation stress, 19 known miRNAs showed an obvious change (fold-change $>2$ and $p$-value <0.05) (Figure 5, Table S2). Of the 19 known miRNAs, 14 miRNAs were upregulated, and 5 miRNAs were down-regulated. The most obvious change was observed for cre-miR1165, whose expression level increased about 45-folds in the TAP-N library compared with that of the TAP library. The expression of cre-miR910, cre-miR911, cremiR1147.1, cre-miR1145.1, and cre-miR1163.1 also showed more than 5-folds increasing in the TAP-N library.

In addition, comparing the standardized sequence reads of the new miRNAs between the two libraries showed that the 10 new miRNA sequences also have significant changes (fold-change $>2$ and $p$-value $<0.05$ ), so there may be differential expression (Tables 2 and S3). Among the 10 predicted novel miRNAs with adjusted expression under nitrogen deprivation stress, 8 miRNAs were upregulated, and 2 miRNAs were downregulated. A total of 2 novel miRNAs (cre-miR-new24 and cre-miR-new25) were only expressed in the TAP library, while 5 novel miRNAs (cre-miR-new26, cre-miR-new27, cremiR-new28, cre-miR-new29, and cre-miR-new30) were only expressed in the TAP-N library. Analysis of the isolation frequencies for these 29 nitrogen deficiency stress-responsive miRNAs, including 19 conserved miRNAs and 10 novel miRNAs, indicated that most of these genes belonged to the less expressed miRNAs, with the isolation frequencies less than 100 TPM. 


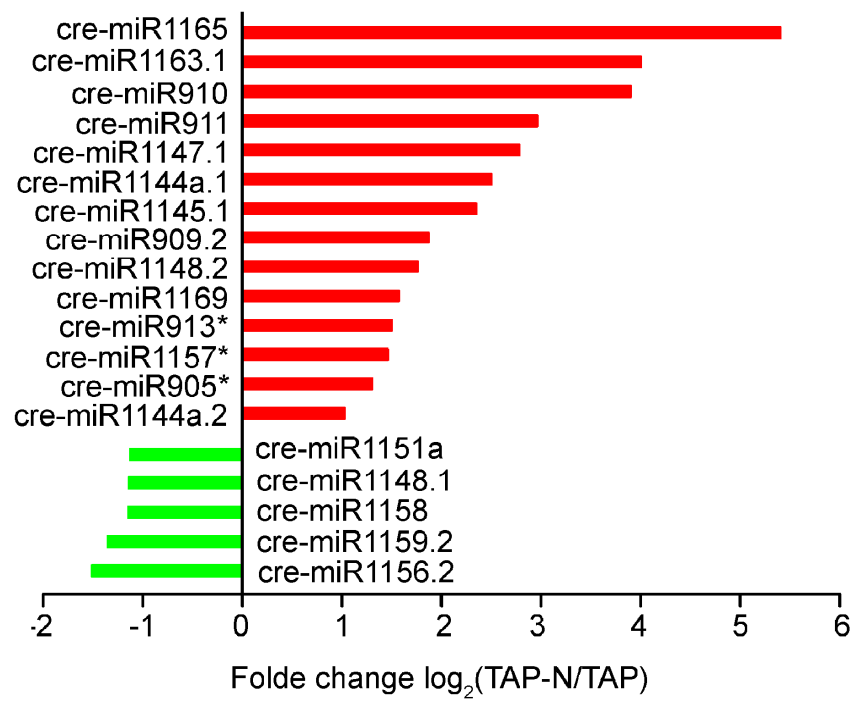

Figure 5. Differentially expressed known miRNAs in response to nitrogen deficiency in C. reinhardtii. The significantly differentially expressed miRNAs with greater than 2-fold relative change and $p$-value $<0.05$ are shown. ${ }^{*} p<0.05$.

Table 2. Expression changes of predict novel miRNAs in response to nitrogen deprivation stress in $C$. reinhardtii. TAP represents normalized expression level of novel miRNAs of $C$. reinhardtii cultivated in nitrogen-replete medium; TAP-N represents normalized expression level of novel miRNAs of $C$. reinhardtii cultivated in nitrogen-depleted medium; * fold-change $\left(\log _{2}\right)>1$ or fold-change $\left(\log _{2}\right)<$ -1 , and $0.01<p$-value $<0.05 ;{ }^{* *}$ fold-change $\left(\log _{2}\right)>1$ or fold-change $\left(\log _{2}\right)<-1$, and $p$-value $<0.01$; $-{ }^{1}$ specifically expressed in TAP-N library; $+^{2}$ specifically expressed in TAP library.

\begin{tabular}{|c|c|c|c|c|c|}
\hline \multirow{2}{*}{ Novel miRNA Name } & \multicolumn{2}{|c|}{ Normalized Expressio (TPM) } & \multirow{2}{*}{$\begin{array}{c}\text { Fold-Change } \\
\left(\log _{2} \text { (TAP-N/TAP)) }\right.\end{array}$} & \multirow{2}{*}{$p$-Value } & \multirow{2}{*}{ Sig-Lable } \\
\hline & TAP & TAP-N & & & \\
\hline cre-miR-new1 & 0.65 & 1.17 & 0.8381 & 0.163 & \\
\hline cre-miR-new2 & 64.68 & 33.15 & -0.9644 & $7.98 \times 10^{-34}$ & \\
\hline cre-miR-new3 & 34.08 & 22.85 & -0.5765 & $1.89 \times 10^{-8}$ & \\
\hline cre-miR-new4 & 129.80 & 88.87 & -0.5464 & $1.38 \times 10^{-25}$ & \\
\hline cre-miR-new5 & 2.47 & 16.33 & 2.7280 & $2.96 \times 10^{-13}$ & $* *$ \\
\hline cre-miR-new6 & 1.23 & 1.51 & 0.2926 & 0.542 & \\
\hline cre-miR-new7 & 95.14 & 123.33 & 0.3744 & 0 & \\
\hline cre-miR-new8 & 0.87 & 4.60 & 2.4017 & $3.45 \times 10^{-7}$ & ** \\
\hline cre-miR-new9 & 0.65 & 1.44 & 1.1430 & 0.046 & $*$ \\
\hline cre-miR-new 10 & 0.87 & 1.10 & 0.3356 & 0.553 & \\
\hline cre-miR-new11 & 88.39 & 139.45 & 0.6578 & $1.41 \times 10^{-13}$ & \\
\hline cre-miR-new12 & 1.89 & 3.23 & 0.7748 & 0.026 & \\
\hline cre-miR-new 13 & 7.90 & 7.89 & -0.0021 & 0.989 & \\
\hline cre-miR-new14 & 33.28 & 9.95 & -1.7418 & $5.51 \times 10^{-43}$ & ** \\
\hline cre-miR-new15 & 179.25 & 170.61 & -0.0712 & 0.08 & \\
\hline cre-miR-new16 & 3.55 & 7.76 & 1.1261 & $2.23 \times 10^{-6}$ & ** \\
\hline cre-miR-new17 & 0.65 & 3.02 & 2.2101 & $4.22 \times 10^{-6}$ & $* *$ \\
\hline cre-miR-new 18 & 8.77 & 20.11 & 1.1965 & $3.55 \times 10^{-14}$ & $* *$ \\
\hline cre-miR-new19 & 365.68 & 132.11 & -1.4688 & 0 & $* *$ \\
\hline cre-miR-new 20 & 5.80 & 73.84 & 3.6701 & 0 & $* *$ \\
\hline cre-miR-new21 & 18.20 & 23.95 & 0.3961 & $8.60 \times 10^{-4}$ & \\
\hline cre-miR-new22 & 72.66 & 142.06 & 0.9674 & $2.63 \times 10^{-13}$ & \\
\hline cre-miR-new 23 & 24.58 & 50.79 & 1.0468 & $1.79 \times 10^{-13}$ & $* *$ \\
\hline cre-miR-new 24 & 0.00 & 4.25 & -1 & $2.22 \times 10^{-16}$ & \\
\hline cre-miR-new 25 & 0.00 & 12.63 & -1 & $2.22 \times 10^{-16}$ & \\
\hline cre-miR-new26 & 7.18 & 0.00 & $t^{2}$ & $9.70 \times 10^{-32}$ & \\
\hline cre-miR-new 27 & 5.44 & 0.00 & $t^{2}$ & $3.18 \times 10^{-24}$ & \\
\hline cre-miR-new 28 & 17.98 & 0.00 & $t^{2}$ & $2.13 \times 10^{-78}$ & \\
\hline cre-miR-new29 & 29.80 & 0.00 & $t^{2}$ & $1.93 \times 10^{-129}$ & \\
\hline cre-miR-new30 & 44.88 & 0.00 & $+^{2}$ & $1.42 \times 10^{-194}$ & \\
\hline
\end{tabular}




\subsection{The Target of Nitrogen Deficiency-Responsive miRNAs and KOGs Analysis}

To understand the 19 conserved miRNAs and 10 novel miRNAs biological function for the nitrogen deficiency responsive (Figure 4 and Table 2), potential C. reinhardtii targets using the Filtered Gene Set transcripts (Release v4.0) of the C. reinhardtii genome sequence (http:/ / genome.jgi-psf.org/Chlre4/Chlre4.download.ftp.html, accessed on 12 June 2021) was computationally predicted. The computational pipeline predicted 204 unique putative genes that were targeted by 29 nitrogen deficiency-responsive miRNAs sequences (Table S4).

The putative target genes subjected to the eukaryotic orthologous groups of proteins (KOG) analysis identified the biological processes actively regulated by the nitrogen deficiency-responsive miRNAs in C. reinhardtii. The targets were annotated by using the KOG annotations available from the Chlre4_KOG (http:/ / genome.jgi-psf.org/Chlre4 /Chlre4.download.ftp.html, accessed on 12 June 2021).

The putative target genes were found involved in a wide variety of biological processes. These were the four uniquely assigned main KOG classes $(31.50 \%$ for "Cellular Processes and Signaling", 15.35\% for "Information Storage and Processing", 36.61\% for "Metabolism", 16.54\% for "Poorly characterized"). The main represented sub-categories were "Signal transduction mechanisms" (12.60\%) in the "Cellular Processes and Signaling" main class, "General function prediction only" (10.24\%) in "Poorly Characterized" main class, "Transcription" (7.48\%) in "Information Storage and Processing" main class and "Lipid transport and metabolism" (7.09\%) of the "Metabolism" main class (Figure 6).
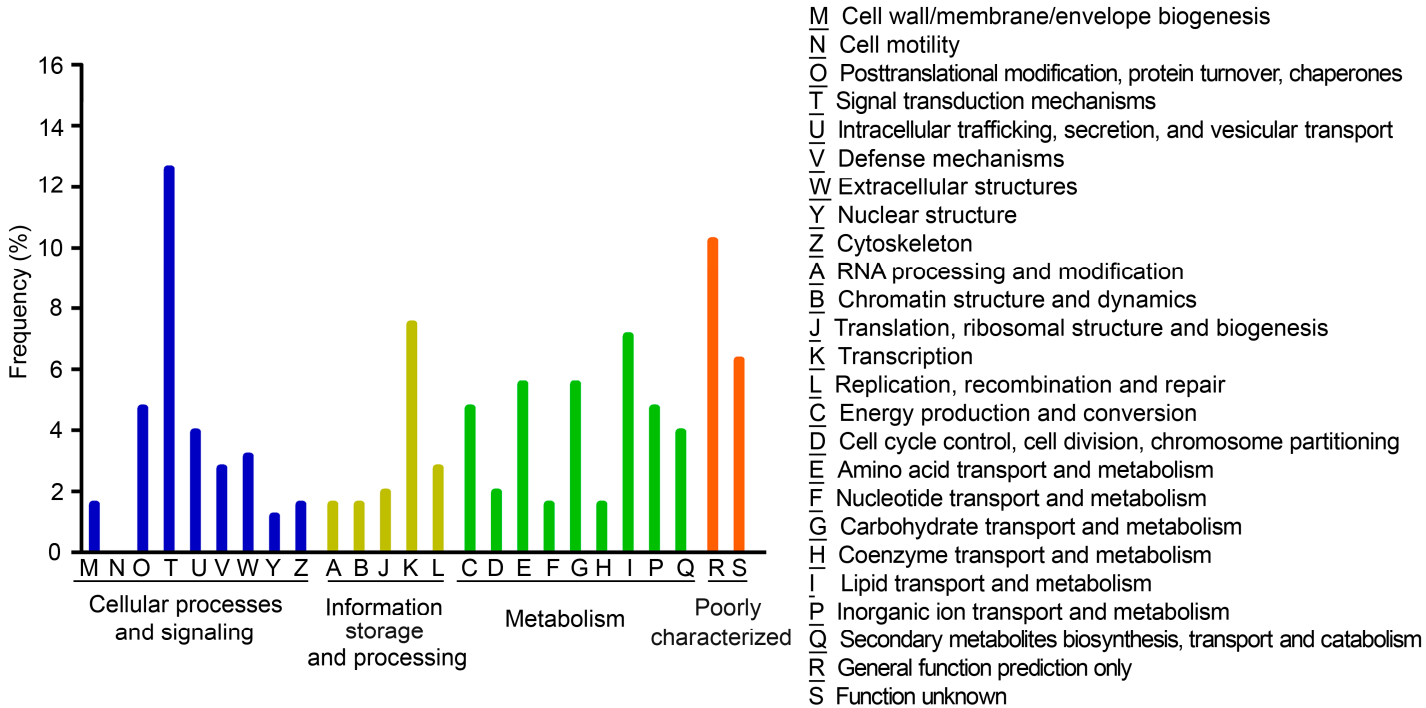

Figure 6. Functional assignments to the KOG categories. The graph shows the assignment of the targets of the nitrogen deficiency-responsive miRNAs in C. reinhardtii to the 25 categories of the eukaryotic orthologous groups of proteins (KOG). The main KOG categories are represented in different colors. The nitrogen deficiency-responsive miRNAs included 19 known miRNAs and 10 novel miRNAs.

Particularly, 13 targets genes of the nitrogen deficiency-responsive miRNAs attend lipid transport and metabolism pathways (Table 3). This result indicated that some nitrogen deficiency-responsive miRNAs might play a role in lipid metabolism cascades through regulating the activity of their target genes. To understand the role of miRNAs in lipid metabolism cascades, we further performed a deep-sequencing approach to determine the expression patterns of putative 13 target genes that are involved in lipid transport and metabolism pathways, which investigate the correlation of miRNAs and these predicted targets [41]. After miRNAs analysis, we determined the fold changes of the target genes in C. reinhardtii under nitrogen deficiency stress. Apart from a few exceptions, 11 of 13 
miRNAs-target gene pairs studied in C. reinhardtii showed opposite expression patterns in response to nitrogen deficiency stress, which is consistent with miRNAs function in guiding the cleavage of target mRNAs. However, positive correlations were also observed between cre-miR910/cre-miR1163 and their putative target acyl-CoA oxidase/START domain-containing proteins, respectively. The positive correlation indicates that the $\mathrm{miR}$ NAs were coexpressed with their targets, which speculate miRNAs related to suppress the encoded protein translation of their targets rather than by leading mRNA cleavage [42].

Table 3. Validation of the predicted genes involved in lipid transport and metabolism targeted by nitrogen deficiency-responsive miRNAs through high-throughput sequencing.

\begin{tabular}{|c|c|c|c|c|c|c|}
\hline \multicolumn{3}{|c|}{ miRNA Expression } & \multicolumn{4}{|c|}{ Target Gene Expression } \\
\hline miRNA & Fold Change & Expression & Gene Product & Fold Change & Expression & $p$-Value \\
\hline cre-miR1156.2 & 0.35 & Down & Prosaposin & 2.17 & Up & 0 \\
\hline \multirow{2}{*}{ cre-miR1144a.2 } & \multirow{2}{*}{2.04} & \multirow{2}{*}{ Up } & SAM-dependent methyltransferases & 0.07 & Down & $2.12 \times 10^{-38}$ \\
\hline & & & $\begin{array}{l}\text { Animal-type fatty acid synthase and } \\
\text { related proteins }\end{array}$ & 0.24 & Down & 0.302 \\
\hline \multirow[t]{2}{*}{ cre-miR1157* } & \multirow[t]{2}{*}{1.25} & \multirow[t]{2}{*}{$\mathrm{Up}$} & $\begin{array}{c}\text { Cytochrome P450 CYP4/CYP19/CYP26 } \\
\text { subfamilies }\end{array}$ & 0.76 & Down & 0.284 \\
\hline & & & Fatty acid desaturase & 0.28 & Down & $4.921 \times 10^{-2}$ \\
\hline \multirow[t]{2}{*}{ cre-miR1163.1 } & \multirow[t]{2}{*}{16.71} & \multirow[t]{2}{*}{$\mathrm{Up}$} & Sterol C5 desaturase & 0.86 & Down & 0.611 \\
\hline & & & START domain-containing proteins & 1.25 & Up & $1.55 \times 10^{-3}$ \\
\hline cre-miR1169 & 2.98 & Up & Lysophospholipase & 0.60 & Down & 0.135 \\
\hline cre-miR910 & 15.55 & $\mathrm{Up}$ & acyl-CoA oxidase & 1.34 & Up & $4.70 \times 10^{-2}$ \\
\hline cre-miR-new5 & 6.61 & Up & Putative phosphoinositide phosphatase & 0.35 & Down & 0.146 \\
\hline cre-miR-new14 & 0.30 & Down & 3-Methylcrotonyl-CoA carboxylase & 3.66 & Up & 0 \\
\hline cre-miR-new16 & 2.19 & Up & Long-chain acyl-CoA transporter & 0.46 & Down & $4.66 \times 10^{-3}$ \\
\hline cre-miR-new19 & 0.36 & Down & Acyl-CoA synthetase & 4.13 & Up & $3.24 \times 10^{-12}$ \\
\hline
\end{tabular}

\section{Discussion}

Recently, the investigation of algae miRNAs has gained more attention due to their vital function in metabolic processes and adaptation to various stresses. Currently, different algae miRNAs genes, including Chlamydomonas reinhardtii [43-45], Chlorella sorokiniana [46], and Botryococcus braunii [47], have been identified, and some of them also have been well characterized. However, the role of miRNAs in lipid accumulation under nitrogen deprivation stress for microalgae is still unclear.

In this work, a total number of 109 miRNAs were detected in the growth of C.reinhardtii in both nitrogen-replete (TAP $+\mathrm{N}$ ) and nitrogen-depleted (TAP-N) conditions. C. reinhardtii miRNAs identified in the present study provided more information in the miRNAs profiling. The Solexa deep-sequencing approach used in this work may be more sensitive enough to detect more miRNAs expressed at a very low level in C. reinhardtii. Besides these known miRNAs, 30 novel miRNAs were found out by Solexa deep sequencing, which increased the number of accounts of $C$. reinhardtii miRNAs families. The 109 miRNAs were compared with genomes of species representing important lineages for investigating their evolutionary roles in other organisms. No homolog of these C. reinhardtii miRNAs was found in other organisms, suggesting that these miRNAs are C. reinhardtii-specific miRNAs, and there $C$. reinhardtii miRNAs may be evolved in an independent way, which coincided with the previous reports [48]. Different from higher eukaryotes, most miRNAs are high evolutionarily conserved in related species. These nonconserved C. reinhardtii miRNAs may play a more species-specific role [49].

Although some miRNAs are stress-regulated and involved in plant responses to nutrient deprivation [25], little information is available for microalgae in this area. This study on the nitrogen deprivation-responsive miRNAs in C. reinhardtii will provide a piece of useful information for understanding the molecular mechanism of lipid accumulation under nitrogen deficiency stress for microalgae. Similar to the previous research in plants [50], the results in this study showed that most of miRNAs expression in C. reinhardtii were affected by nitrogen deficiency stress, which indicated that the nitrogen response process 
is complex and requires a large number of miRNAs to participate in transcriptional and post-transcriptional gene expression regulation [51]. Interestingly, several reported sulfur deprivation-responsive miRNAs in C. reinhardtii are also involved in nitrogen deprivation stress. For example, cre-miR910, cre-miR1144a.1, cre-miR1147, and cre-miR1148.2 were significantly induced by sulfur deprivation in C. reinhardtii [51]. In this study, cre-miR910, cre-miR1144a.1, cre-miR1147, and cre-miR1148.2 were significantly induced under nitrogen deprivation stress in C. reinhardtii, which indicated these miRNAs may control one of the most critical defense systems for $C$. reinhardtii nutrition deprivation stress.

To better understand the biologic functional implication for the nitrogen deficiencyresponsive miRNAs in $C$. reinhardtii, their targeted mRNAs and function enrichment were investigated. As a result, a total number of 204 potential targeted genes were identified with the rules of target prediction reported by Allen et al. [35]. To evaluate the functional enrichment, these predicted miRNA targets with KOG term annotation were annotated in this study. Predicted miRNA targets populated many KOG categories. Inconsistent with previous studies [15], the most significant KOG terms were genes involved in a signal transduction mechanism, including signal transduction factor casein/tyrosine kinase, actin regulatory protein, sensory transduction histidine kinase, cyclin-dependent kinase inhibitor, and growth factor receptor-bound proteins, indicating the important role of nitrogen deficiency-responsive miRNAs in both signal transduction and post-transcriptional regulation. Furthermore, KOG terms associated with some $C$. reinhardtii transcription factors such as TFIID, SMRT/SMRTER, DEAD-box superfamily, and TAZ Zn-finger proteins, indicating the post-transcription regulation function of nitrogen deficiency-responsive miRNAs.

It is noteworthy that some lipid transport and metabolism biological processes were also enriched in lipid metabolic regulation. The functional annotation chart of target genes for the nitrogen deficiency-responsive miRNAs revealed some factors involved in the regulation of lipids biosynthesis (acyl-CoA synthetase, fatty acid desaturase), lipid transport (long-chain acyl-CoA transporter), and fatty acid beta-oxidation (PristanoylCoA/acyl-CoA oxidase), were all predicted, indicating that various aspects in the lipid metabolic process may be regulated by some nitrogen deficiency-responsive miRNAs in $C$. reinhardtii. A recent study found that under nitrogen stress, $C$. reinhardtii lipids synthesize related proteins: acetyl CoA synthetase, two fatty acid desaturases, and a phospholipaseB-like protein change rapidly, indicating a trend of transformation from metabolism to TAG synthesis at the post-transcriptional level [52], which is consistent with this study. Similarly, LIP4, a putative TAG lipase in C. reinhardtii, is transcriptionally upregulated in the presence of nitrogen deficiency and TAG accumulation [53]. Acyl-CoA oxidase is the target of cre-miR910, and it is the first enzyme in the fatty acid beta-oxidation pathway, which catalyzes the desaturation of acyl-CoAs to 2-trans-enoyl-CoAs. cre-miR1169 targets lysophospholipase in the regulation of glycerophospholipid metabolism. cre-miR1163.1 targets fatty acid desaturase that catalyzes the biosynthesis of highly unsaturated fatty acids (HUFA) from precursor essential fatty acids. cre-miR1144a.2 targets animal-type fatty acid synthase and related proteins. The protein belongs to the beta-ketoacyl-ACP synthases family that catalyzes the condensation of malonyl-ACP with the growing fatty acid chain. cre-miR-new16 targets a long-chain acyl-CoA transporter that catalyzes the pre-step reaction for $\beta$-oxidation of fatty acids or can be incorporated in phospholipids. cremiR-new19 targets acyl-CoA synthetase that catalyzes the conversion of acetate into acetyl $\mathrm{CoA}$ as a precursor for fatty acid synthesis. These results may indicate that the differential expression profile of $C$. reinhardtii miRNAs led to massive changes in gene expression and lipid metabolism closely associated with triacylglycerol (TAG) accumulation of $C$. reinhardtii. Further experiments are needed to verify this hypothesis.

Based on the deep-sequencing technology, 79 knowns and 30 novel miRNAs were discovered from $C$. reinhardtii cells under nitrogen deprivation stress. In addition, deepsequencing technology can be used as a powerful miRNAs expression profiling tool to identify the differentially expressed miRNAs, providing a basis for future miRNAs functions research and elucidating the potential mechanisms of regulating diverse molecular 
and physiological pathways. In this study, a total number of 29 miRNAs show differential responses to nitrogen deficiency stress in C. reinhardtii.

Target predictions revealed that lipid metabolic processes may be affected by changing miRNAs expression, which opens miRNAs tantalizing possibility involved in the lipid biosynthesis cascades. This would have a significant impact on the recent approaches that use miRNAs to increase the accumulation of lipid in microalgae.

\section{Conclusions}

This study proves that under nitrogen stress, the miRNA in Chlamydomonas reinhardtii is differentially expressed, most of which are upregulated. The putative miRNA target gene is predicted by KOG. It is predicted for the first time that 10 miRNAs and their target genes may be involved in lipid transport and metabolic biological processes.

This study provides suggestions on gene regulation to further explain the molecular mechanism of lipid accumulation in Chlamydomonas reinhardtii under nitrogen stress.

As energy pressure continues to increase, the use of biomass oils has received more attention. Microalgae has become an excellent cell factory for obtaining bio-oil due to its low cultivation cost. The use of bioengineering methods to improve the accumulation of microalgae oil and find a balance between microalgae biomass accumulation and oil production is the direction of our next efforts.

Supplementary Materials: The following supporting information can be downloaded at: https: //www.mdpi.com/article/10.3390/bioengineering9010006/s1, Figure S1: Ven chart for unique small RNAs; Figure S2: Ven chart for total small RNAs; Table S1: Summary of the common and specific sequences ( $\geq 18 \mathrm{nt}$ ) between TAP-N and TAP libraries; Table S2: Abundance and differential expression of known miRNAs expressed both in TAP and TAP-N samples; Table S3: predict novel miRNA in our small RNA libraries; Table S4: Complete list of predicted miRNA targets of nitrogen deficiency-responsive miRNA and KOGs annotations.

Author Contributions: Conceptualization, J.Z.; Data curation, J.Z.; formal analysis, J.Z.; investigation, J.Z.; writing-original draft, J.Z.; funding acquisition, B.Z. and R.F.; methodology, C.Y.; resources, X.L.; supervision, X.L.; visualization, G.D.; writing—review and editing, R.F., J.S. and J.Z. All authors have read and agreed to the published version of the manuscript.

Funding: This study was supported by the Natural Science Foundation of China (no. 41106125, 21906139) and the Science and Technology Service Network Initiative Project of the Chinese Academy of Sciences (no. KFJ-STS-QYZX-112).

Data Availability Statement: The data provided in this study can be obtained in the figures and tables in this article and the figures and tables in the supplementary materials.

Acknowledgments: We are grateful to Chlamydomonas Center, Duke University, for providing the C. reinhardtii CC-503 (cw92 mt+) strains and the BGI (Beijing Genomics Institute) for their Solexa sequencing.

Conflicts of Interest: The authors declare no conflict of interest. No role for the funder in the design and conduct of the study.

\section{References}

1. Wang, H.; Zhou, W.; Cheng, W.; Gao, L.; Liu, T. Strategy study on enhancing lipid productivity of filamentous oleaginous microalgae Tribonema. Bioresour. Technol. 2016, 218, 161-166. [CrossRef]

2. Gargouri, M.; Bates, P.D.; Park, J.J.; Kirchhoff, H.; Gang, D.R. Functional photosystem I maintains proper energy balance during nitrogen depletion in Chlamydomonas reinhardtii, promoting triacylglycerol accumulation. Biotechnol. Biofuels 2017, 10, 89. [CrossRef]

3. Tanvir, R.U.; Zhang, J.; Canter, T.; Chen, D.; Lu, J.; Hu, Z. Harnessing Solar Energy using Phototrophic Microorganisms: A Sustainable Pathway to Bioenergy, Biomaterials, and Environmental Solutions. Renew. Sustain. Energy Rev. 2021, 146, 111181. [CrossRef]

4. Hu, Q.; Sommerfeld, M.; Jarvis, E.; Ghirardi, M.; Posewitz, M.; Seibert, M.; Darzins, A. Microalgal triacylglycerols as feedstocks for biofuel production: Perspectives and advances. Plant J. 2008, 54, 621-639. [CrossRef] 
5. Ferreira, V.S.; Pinto, R.F.; Sant'Anna, C. The green microalga S. dimorphus (UTEX 1237) showed an increase in body lipids in N-limited cultures. J. Appl. Microbiol. 2016, 120, 661-670. [CrossRef]

6. Illman, A.M.; Scragg, A.H.; Shales, S.W. Increase in Chlorella strains calorific values when grown in low nitrogen medium. Enzym. Microb. Technol. 2000, 27, 631-635. [CrossRef]

7. Adamakis, I.D.; Lazaridis, P.A.; Terzopoulou, E.; Torofias, S.; Valari, M.; Kalaitzi, P.; Rousonikolos, V.; Gkoutzikostas, D.; Zouboulis, A.; Zalidis, G.; et al. Cultivation, characterization, and properties of Chlorella vulgaris microalgae with different lipid contents and effect on fast pyrolysis oil composition. Environ. Sci. Pollut. Res. Int. 2018, 25, 23018-23032. [CrossRef] [PubMed]

8. Charria-Girón, E.; Amazo, V.; De Angulo, D.; Hidalgo, E.; Villegas-Torres, M.F.; Baganz, F.; Caicedo Ortega, N.H. Strategy for Managing Industrial Anaerobic Sludge through the Heterotrophic Cultivation of Chlorella sorokiniana: Effect of Iron Addition on Biomass and Lipid Production. Bioengineering 2021, 8, 82. [CrossRef] [PubMed]

9. Salomé, P.A.; Merchant, S.S. A Series of Fortunate Events: Introducing Chlamydomonas as a Reference Organism. Plant Cell 2019, 31, 1682-1707. [CrossRef] [PubMed]

10. Blaby, I.K.; Glaesener, A.G.; Mettler, T.; Fitz-Gibbon, S.T.; Gallaher, S.D.; Liu, B.; Boyle, N.R.; Kropat, J.; Stitt, M.; Johnson, S.; et al. Systems-level analysis of nitrogen starvation-induced modifications of carbon metabolism in a Chlamydomonas reinhardtii starchless mutant. Plant Cell 2013, 25, 4305-4323. [CrossRef]

11. Park, J.J.; Wang, H.; Gargouri, M.; Deshpande, R.R.; Skepper, J.N.; Holguin, F.O.; Juergens, M.T.; Shachar-Hill, Y.; Hicks, L.M.; Gang, D.R. The response of Chlamydomonas reinhardtii to nitrogen deprivation: A systems biology analysis. Plant J. 2015, 81, 611-624. [CrossRef]

12. Hernández-Torres, A.; Zapata-Morales, A.L.; Ochoa Alfaro, A.E.; Soria-Guerra, R.E. Identification of gene transcripts involved in lipid biosynthesis in Chlamydomonas reinhardtii under nitrogen, iron and sulfur deprivation. World J. Microbiol. Biotechnol. 2016, 32, 55. [CrossRef]

13. Takeuchi, T.; Sears, B.B.; Lindeboom, C.; Lin, Y.T.; Fekaris, N.; Zienkiewicz, K.; Zienkiewicz, A.; Poliner, E.; Benning, C. Chlamydomonas CHT7 Is Required for an Effective Quiescent State by Regulating Nutrient-Responsive Cell Cycle Gene Expression. Plant Cell 2020, 32, 1240-1269. [CrossRef] [PubMed]

14. Jang, S.; Kong, F.; Lee, J.; Choi, B.Y.; Wang, P.; Gao, P.; Yamano, T.; Fukuzawa, H.; Kang, B.H.; Lee, Y. CrABCA2 Facilitates Triacylglycerol Accumulation in Chlamydomonas reinhardtii under Nitrogen Starvation. Mol. Cells 2020, 43, 48-57. [CrossRef]

15. Miller, R.; Wu, G.; Deshpande, R.R.; Vieler, A.; Gärtner, K.; Li, X.; Moellering, E.R.; Zäuner, S.; Cornish, A.J.; Liu, B.; et al. Changes in transcript abundance in Chlamydomonas reinhardtii following nitrogen deprivation predict diversion of metabolism. Plant Physiol. 2010, 154, 1737-1752. [CrossRef] [PubMed]

16. Luo, Q.; Song, W.; Li, Y.; Wang, C.; Hu, Z. Flagella-Associated WDR-Containing Protein CrFAP89 Regulates Growth and Lipid Accumulation in Chlamydomonas reinhardtii. Front. Plant Sci. 2018, 9, 691. [CrossRef]

17. Philipps, G.; Happe, T.; Hemschemeier, A. Nitrogen deprivation results in photosynthetic hydrogen production in Chlamydomonas reinhardtii. Planta 2012, 235, 729-745. [CrossRef]

18. Zienkiewicz, K.; Du, Z.Y.; Ma, W.; Vollheyde, K.; Benning, C. Stress-induced neutral lipid biosynthesis in microalgae-Molecular, cellular and physiological insights. Biochim. Biophys. Acta Mol. Cell Biol. Lipids 2016, 1861, 1269-1281. [CrossRef] [PubMed]

19. Yang, M.; Meng, Y.; Chu, Y.; Fan, Y.; Cao, X.; Xue, S.; Chi, Z. Triacylglycerol accumulates exclusively outside the chloroplast in short-term nitrogen-deprived Chlamydomonas reinhardtii. Biochim. Biophys. Acta Mol. Cell Biol. Lipids 2018, 1863, $1478-1487$. [CrossRef]

20. Jones-Rhoades, M.W.; Bartel, D.P.; Bartel, B. MicroRNAS and their regulatory roles in plants. Annu. Rev. Plant Biol. 2006, 57, 19-53. [CrossRef]

21. Zhao, T.; Li, G.; Mi, S.; Li, S.; Hannon, G.J.; Wang, X.J.; Qi, Y. A complex system of small RNAs in the unicellular green alga Chlamydomonas reinhardtii. Genes Dev. 2007, 21, 1190-1203. [CrossRef] [PubMed]

22. Bartel, D.P. MicroRNAs: Genomics, biogenesis, mechanism, and function. Cell 2004, 116, 281-297. [CrossRef]

23. Zhang, T.; Li, Z.; Song, X.; Han, L.; Wang, L.; Zhang, J.; Long, Y.; Pei, X. Identification and Characterization of microRNAs in the Developing Seed of Linseed Flax (Linum usitatissimum L.). Int. J. Mol. Sci. 2020, 21, 2708. [CrossRef] [PubMed]

24. Yu, Y.; Wu, G.; Yuan, H.; Cheng, L.; Zhao, D.; Huang, W.; Zhang, S.; Zhang, L.; Chen, H.; Zhang, J.; et al. Identification and characterization of miRNAs and targets in flax (Linum usitatissimum) under saline, alkaline, and saline-alkaline stresses. BMC Plant Biol. 2016, 16, 124. [CrossRef] [PubMed]

25. Sunkar, R.; Chinnusamy, V.; Zhu, J.; Zhu, J.K. Small RNAs as big players in plant abiotic stress responses and nutrient deprivation. Trends Plant Sci. 2007, 12, 301-309. [CrossRef]

26. Li, T.; Li, H.; Zhang, Y.X.; Liu, J.Y. Identification and analysis of seven $\mathrm{H}_{2} \mathrm{O}_{2}$-responsive miRNAs and 32 new miRNAs in the seedlings of rice (Oryza sativa L. ssp. indica). Nucleic Acids Res. 2011, 39, 2821-2833. [CrossRef]

27. Xu, P.; Vernooy, S.Y.; Guo, M.; Hay, B.A. The Drosophila microRNA Mir-14 suppresses cell death and is required for normal fat metabolism. Curr. Biol. 2003, 13, 790-795. [CrossRef]

28. Goedeke, L.; Rotllan, N.; Canfrán-Duque, A.; Aranda, J.F.; Ramírez, C.M.; Araldi, E.; Lin, C.S.; Anderson, N.N.; Wagschal, A.; de Cabo, R.; et al. MicroRNA-148a regulates LDL receptor and ABCA1 expression to control circulating lipoprotein levels. Nat. Med. 2015, 21, 1280-1289. [CrossRef] 
29. Horie, T.; Nishino, T.; Baba, O.; Kuwabara, Y.; Nakao, T.; Nishiga, M.; Usami, S.; Izuhara, M.; Nakazeki, F.; Ide, Y.; et al. MicroRNA-33b knock-in mice for an intron of sterol regulatory element-binding factor 1 (Srebf1) exhibit reduced HDL-C in vivo. Sci. Rep. 2014, 4, 5312. [CrossRef]

30. Barvkar, V.T.; Pardeshi, V.C.; Kale, S.M.; Qiu, S.; Rollins, M.; Datla, R.; Gupta, V.S.; Kadoo, N.Y. Genome-wide identification and characterization of microRNA genes and their targets in flax (Linum usitatissimum): Characterization of flax miRNA genes. Planta 2013, 237, 1149-1161. [CrossRef]

31. Escorcia, W.; Ruter, D.L.; Nhan, J.; Curran, S.P. Quantification of Lipid Abundance and Evaluation of Lipid Distribution in Caenorhabditis elegans by Nile Red and Oil Red O Staining. J. Vis. Exp. 2018, 133, 57352. [CrossRef]

32. Chen, W.; Zhang, C.; Song, L.; Sommerfeld, M.; Hu, Q. A high throughput Nile red method for quantitative measurement of neutral lipids in microalgae. J. Microbiol. Methods 2009, 77, 41-47. [CrossRef] [PubMed]

33. Chen, M.; Tang, H.; Ma, H.; Holland, T.C.; Ng, K.Y.; Salley, S.O. Effect of nutrients on growth and lipid accumulation in the green algae Dunaliella tertiolecta. Bioresour. Technol. 2011, 102, 1649-1655. [CrossRef] [PubMed]

34. Bligh, E.G.; Dyer, W.J. A rapid method of total lipid extraction and purification. Can. J. Biochem. Physiol. 1959, 37, 911-917. [CrossRef] [PubMed]

35. Allen, E.; Xie, Z.; Gustafson, A.M.; Carrington, J.C. MicroRNA-directed phasing during trans-acting siRNA biogenesis in plants. Cell 2005, 121, 207-221. [CrossRef]

36. Li, G.; Li, Y.; Li, X.; Ning, X.; Li, M.; Yang, G. MicroRNA identity and abundance in developing swine adipose tissue as determined by Solexa sequencing. J. Cell Biochem. 2011, 112, 1318-1328. [CrossRef]

37. Xin, M.; Wang, Y.; Yao, Y.; Xie, C.; Peng, H.; Ni, Z.; Sun, Q. Diverse set of microRNAs are responsive to powdery mildew infection and heat stress in wheat (Triticum aestivum L.). BMC Plant Biol. 2010, 10, 123. [CrossRef] [PubMed]

38. Schwab, R.; Palatnik, J.F.; Riester, M.; Schommer, C.; Schmid, M.; Weigel, D. Specific effects of microRNAs on the plant transcriptome. Dev. Cell 2005, 8, 517-527. [CrossRef]

39. Liu, J.; Huang, J.; Sun, Z.; Zhong, Y.; Jiang, Y.; Chen, F. Differential lipid and fatty acid profiles of photoautotrophic and heterotrophic Chlorella zofingiensis: Assessment of algal oils for biodiesel production. Bioresour. Technol. 2011, 102, 106-110. [CrossRef]

40. Liang, C.; Zhang, X.; Zou, J.; Xu, D.; Su, F.; Ye, N. Identification of miRNA from Porphyra yezoensis by high-throughput sequencing and bioinformatics analysis. PLOS ONE 2010, 5, e10698. [CrossRef]

41. González-Ballester, D.; Casero, D.; Cokus, S.; Pellegrini, M.; Merchant, S.S.; Grossman, A.R. RNA-seq analysis of sulfur-deprived Chlamydomonas cells reveals aspects of acclimation critical for cell survival. Plant Cell 2010, 22, 2058-2084. [CrossRef] [PubMed]

42. Ren, J.; Jin, P.; Wang, E.; Marincola, F.M.; Stroncek, D.F. MicroRNA and gene expression patterns in the differentiation of human embryonic stem cells. J. Transl. Med. 2009, 7, 20. [CrossRef] [PubMed]

43. Molnár, A.; Schwach, F.; Studholme, D.J.; Thuenemann, E.C.; Baulcombe, D.C. miRNAs control gene expression in the single-cell alga Chlamydomonas reinhardtii. Nature 2007, 447, 1126-1129. [CrossRef] [PubMed]

44. Voshall, A.; Kim, E.J.; Ma, X.; Yamasaki, T.; Moriyama, E.N.; Cerutti, H. miRNAs in the alga Chlamydomonas reinhardtii are not phylogenetically conserved and play a limited role in responses to nutrient deprivation. Sci. Rep. 2017, 7, 5462. [CrossRef]

45. Valli, A.A.; Santos, B.A.; Hnatova, S.; Bassett, A.R.; Molnar, A.; Chung, B.Y.; Baulcombe, D.C. Most microRNAs in the single-cell alga Chlamydomonas reinhardtii are produced by Dicer-like 3-mediated cleavage of introns and untranslated regions of coding RNAs. Genome Res. 2016, 26, 519-529. [CrossRef]

46. Azaman, S.N.A.; Satharasinghe, D.A.; Tan, S.W.; Nagao, N.; Yusoff, F.M.; Yeap, S.K. Identification and Analysis of microRNAs in Chlorella sorokiniana Using High-Throughput Sequencing. Genes 2020, 11, 1131. [CrossRef]

47. Deng, X.-Y.; Hu, X.-L.; Li, D.; Wang, L.; Cheng, J.; Gao, K. Identification and analysis of microRNAs in Botryococcus braunii using high-throughput sequencing. Aquat. Biol. 2017, 26, 41-48. [CrossRef]

48. Siomi, H.; Siomi, M.C. Expanding RNA physiology: MicroRNAs in a unicellular organism. Genes Dev. 2007, $21,1153-1156$. [CrossRef]

49. Sunkar, R.; Zhu, J.K. Novel and stress-regulated microRNAs and other small RNAs from Arabidopsis. Plant Cell 2004, 16 2001-2019. [CrossRef]

50. Zhao, M.; Tai, H.; Sun, S.; Zhang, F.; Xu, Y.; Li, W.X. Cloning and characterization of maize miRNAs involved in responses to nitrogen deficiency. PLoS ONE 2012, 7, e29669. [CrossRef]

51. Shu, L.; Hu, Z. Characterization and differential expression of microRNAs elicited by sulfur deprivation in Chlamydomonas reinhardtii. BMC Genom. 2012, 13, 108. [CrossRef] [PubMed]

52. Smythers, A.L.; McConnell, E.W.; Lewis, H.C.; Mubarek, S.N.; Hicks, L.M. Photosynthetic Metabolism and Nitrogen Reshuffling Are Regulated by Reversible Cysteine Thiol Oxidation Following Nitrogen Deprivation in Chlamydomonas. Plants 2020, 9, 784. [CrossRef] [PubMed]

53. Warakanont, J.; Li-Beisson, Y.; Benning, C. LIP4 Is Involved in Triacylglycerol Degradation in Chlamydomonas reinhardtii. Plant Cell Physiol. 2019, 60, 1250-1259. [CrossRef] [PubMed] 